\title{
Study on Spatial Model and Service Radius of Rural Areas and Agriculture Information Level in Yellow-River Delta
}

\author{
Yujian Yang ${ }^{1, *}$, Guangming Liu ${ }^{2}$, Xueqin Tong ${ }^{1}$, and Zhicheng Wang ${ }^{1}$ \\ ${ }^{1} \mathrm{~S} \& \mathrm{~T}$ Information Engineering Technology Center of Shandong Academy of Agricultural \\ Science, Information center of agronomy College of Shandong University Jinan 250100, \\ P.R. China \\ yyjtshkh@gmail.com \\ ${ }^{2}$ Institute of Soil Science, Chinese Academy of Sciences, Nanjing 210008, P.R. China
}

\begin{abstract}
Based on the evaluation methods and systems of information measurement level, and according to the principles of agriculture information subject, the study constructed 13 indices system for the measurement of the rural areas and agriculture information level in Yellow-river Delta in 2007. Spatial autocorrelation model of rural areas and agriculture information of 19 country units showed that the comprehensive information level of Hanting, Shouguang, Guangrao, Bincheng, Huimin, Wudi and Yangxin country unit is very significant, has the obvious spatial agglomeration and homogeneity characteristics, but information level agglomeration of Kenli country and Zouping city has the significant heterogeneity, and information level agglomeration characteristics of other 10 country units is not significant. The radius surface of the complicated information level from radial basis function model indicated that rural areas and agriculture information service has a certain service radius, the distance of service radius in theory is $30 \mathrm{Km}$, the gradient and hierarchy is obvious. According to it, the comprehensive service node should be established in Bincheng district and the secondary service node should be set up in Wudi country for improving the service efficiency. Combining with GIS grid technology, the profile line results of rural areas and agriculture information service from centroid coordinates based on 19 country units illustrated the fluctuation characteristics of the comprehensive information level. For yellow-river Delta, the high-efficiency ecological zone construction should consider the gradients of information service, continuity of information service and spatial agglomeration characteristics of 19 country units. Correspondingly, the regional policy which reflected the regional difference and association characteristics was carried out to achieve the leap development.
\end{abstract}

Keywords: Rural areas and agriculture information level, Service Radius, Measurement indices, Radial basis function, Yellow-river Delta.

* Corresponding author. 


\section{Introduction}

Rural areas and agriculture Information is not only the inevitable trend of the modern agricultural development, but also an important component of the national economy information (Zang Chunrong et al., 2004). Rural areas and agriculture information assessment is to evaluate the level and effect of rural information construction and development level by adopting mathematical statistics(such as AHP method, fuzzy theory study), operation research principle and specific indicator system (Liu Shihong et al., 2007; Du Jing et al., 2010). Evaluating rural information level comprehensively, measuring and grasping the information development level accurately will help to find problems and shortcomings in the process of rural information. Rural information assessment is a huge system engineering that synthesizes technological and institutional innovations. Its implementation involves all aspects of rural business and information technology (Qin Xiangyang et al., 2008)[1,2,3,4,5,6,7]. Rural areas and agriculture information constructions reflected the science and technology progress and the main promotion power of agriculture economy(Chen Xiwen, 2010), the present study showed that the correlation domains involved in the evaluation indices system of rural areas and agriculture information, but the measurement evaluation of it should be strengthened on the regional scale to intensify the agriculture resources and high-efficiency utilization of rural areas and agriculture information. The regional measurement of rural areas and agriculture information expanded the open degree and propelled the regional economy development, the service scope and service radius study of information level is rarely on the regional scale from the correlation documents[8].

There is crucial to select the service node of rural areas and agriculture information level, whether in theory, or in practice for the comprehensive service system of information level. The study selected the regional economy body-Yellow river delta, as demonstration site, and explored the regional effects of rural areas and agriculture information level. Furthermore, the gradient and hierarchy of rural areas and agriculture information service was developed in the study, with the support of spatial analysis technology, the important service node of rural area and agriculture information level where the suitable location is selected was analyzed to improve the service efficiency in Yellow river delta. And other emphasis study is the fluctuation characteristics of the comprehensive information level of 19 country units in the paper.

\section{Material and Methodology}

\subsection{Study Area and Indices System Establishment}

Yellow river delta was formed on the basis of the yellow river alluvial plain and the adjacent marine regions in the north parts of Shandong province, extension the round regions, including Dongying city, Binzhou city, Hanting, Shouguang city, Changyi city in Weifang city, Leling and Qingyun in Dezhou city, Gaoqing in Zibo city and Laizhou in Yantai city. The total area is $26500 \mathrm{Km}^{2}$, the $1 / 6$ of the total province. Yellow river Delta is the high-efficiency ecological zone, which has the important strategic significance, it located in the north emphasis of the whole strategy in Shandong 
province and is the important part of "blue economic zone of peninsula", the comprehensive development of rural areas and agriculture information level in Shandong province is crucial part of the national demonstration province of rural areas and agriculture information on $11^{\text {th }}$ and $12^{\text {th }}$ five year development planning of China.

Indices system establishment of rural areas and agriculture information referred to the new countryside planning of socialism construction from development and reform commission of Shandong province "developed production, affluent life, civilized rural atmosphere, clean and tidy village and democratic administration." Combing with well-off indices from Wu Dianting (2006), and considering the measurement system rule, study data were effectively collected and the selected 13 indices was applied in the study[9].The 6 indices reflected material life (Enger coefficient, per house area of household, tap water countryside, household car, hospital numbers, urbanization). The 3 indices reflected spiritual life (telephone communication countryside, cable television countryside, patents per year). The income and distribution situation, included 2 indices (per capita net income and per capita GDP. Population quality considered 2 indices (students in middle school and per capita expenditure of education, science-technology and culture). In circumstances, Data acquisition, elimination dimension, the determination of indices weight, model establishment, the comprehensive indices computerization and comparison analysis, a series of steps were carried out to deal with the correlation data. As mentioned, measurement indices system was used to explore the autocorrelation characteristics and service radius of rural areas and agriculture information level[10,11].

\subsection{Moran's I Coefficient and Radial Basis Function}

Spatial autocorrelation can be defined as the coincidence of value similarity with site similarity. As the name suggests, autocorrelation is the correlation of a variable with itself, the autocorrelation coefficient (Moran's I) was used as description about the spatial dependency and was selected to describe the correlation degree of the location attribution value. The Moran's I coefficient is given by:

$$
I=\frac{n \sum \sum\left(x_{i}-\bar{x}\right)}{W \sum\left(x_{i}-\bar{x}\right)^{2}}
$$

Where $x_{i}$ is the data value at location $i, h$ is the distance between locations $i$ and $j$, $w_{i j}$ takes 1 if the pair $(i, j)$ pertains to distance class $h$ (the one for which the coefficient is computed), otherwise $0, W$ is the sum of $w_{i j}$. Where: $I \in[-1,1], I=0$ stands for the independent variables, $I>0$ stands for the positive correlation, $I<0$ stands for the negative correlation[12,13,14]. Moran's I coefficient reflecting spatial dependency embodied the similarity of nearby observations. If high values of an attribute tend to cluster together in some parts of country unit and low values tend to cluster together in other parts, the attribute is said to exhibit positive spatial autocorrelation. Conversely, if high values tend to be found in close proximity to low values and vice versa, the attribute is said to exhibit negative spatial autocorrelation[15]. 
Radial basis function (RBF) enables you to create a surface that captures global trends and picks up the local variation, which helps in cases where fitting a plane to the sample values will not accurately represent the surface. To create the surface, suppose you have the ability to bend and stretch the predicted surface so that it passes through all of the measured values. The study uses a set of $\mathrm{n}$ basis functions, one for each data location. The predictor is a linear combination of the basis functions.

$$
\hat{Z}\left(s_{0}\right)=\sum_{i=1}^{n} \omega_{i} \phi\left(\left\|s_{i}-s_{0}\right\|\right)+\omega_{n+1}
$$

Where $\phi(r)$ is a radial basis function, $r=\left\|s_{i}-s_{0}\right\|$ is Euclidean distance between the prediction location $s_{0}$ and each data location $s_{i}$ and $\left\{\omega_{i}: i=1,2,3 \cdots, n+1\right\}$ are weights to be estimated, $\omega_{n+1}$ is a bias parameter[16].

RBF methods are a series of exact interpolation techniques, that is, the surface must go through each measured sample value. RBF are conceptually similar to fitting a rubber membrane through the measured sample values while minimizing the total curvature of the surface. The selected basis function determines how the rubber membrane will fit between the values. RBF can predict values above the maximum and below the minimum measured values as in the cross section below. The optimal parameter is determined using cross-validation in a similar manner. The RBF are also used for calculating smooth surfaces from data points. The functions produce good results for gently varying surfaces[17].

\section{$3 \quad$ Results and Analysis}

\subsection{Moran's I Coefficient Analysis}

The heterogeneity and dependence of rural areas and agriculture information level was analyzed by Moran`s I computerization, Moran`s I value is 0.2424 , the positive spatial autocorrelation, Monte-Carlo tests showed the significant correlation of information level in confidence interval of $99 \%$, the rural areas and agriculture information measurement on basis of 19 country units has the strong agglomeration characteristics in Yellow river delta in 2007. As illustrated in Fig. 1.

Hanting, Shouguang and Guangrao(High-High), which displays the country units with a high information level (above the average) surrounded by country units with high information level (above the average) Bincheng, Huimin, Wudi and Yangxin( LowLow), which presented the country units with low information level surrounded by country units with low information level. In the study, information level of the 7 country units presented the spatial clustering and homogeneity, information level of Kenli (LowHigh) country showed the country units with low value surrounded by country units with high values, the evident difference existed in them. Zouping (High-Low) shows the country units with high value of information indices surrounded by country units with low value of information indices, the two country units presented the heterogeneity. The other information indices of 10 country units has not obvious significance. 


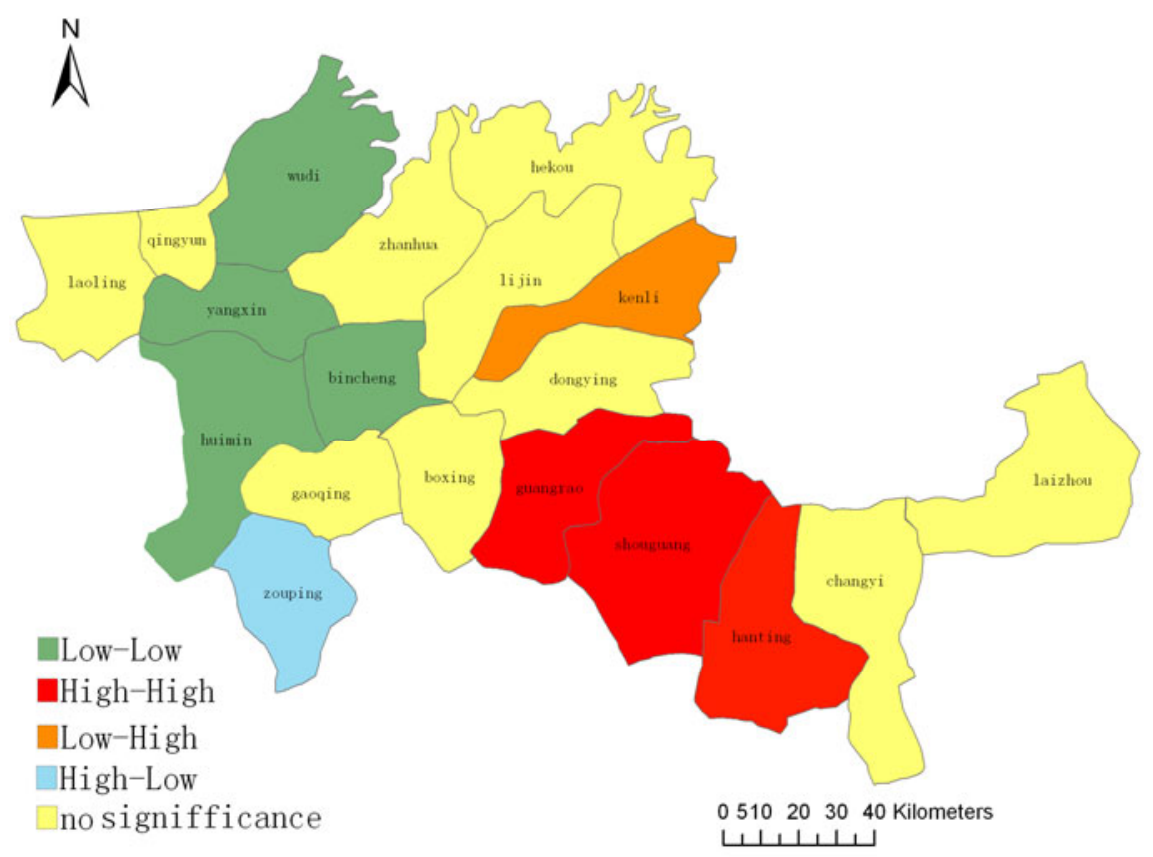

Fig. 1. Scatterplot map of measurement indices of rural areas and agriculture information level

The regional spatial pattern of rural areas and agricultural information undertook the historical consistence, the better economic foundation, relative location advantage and the regional development policy, these factors have a large effect on the spatial pattern of rural areas and agricultural information level. Combining with Moran`s I computerization results, showed that Hanting, Shouguang and Guangrao has the high level of information level, promoting the information coordination development of the surrounding country units, such as Zouping city, Kenli country. For the low information level of Bincheng district, Huimin country, Wudi country and Yangxin country, should mainly depend on the sparking sites of rural areas and agricultural information to promote service efficiency. Especially, the policy power has a large effect on shortening the difference.

\subsection{Service Radius Surface}

Clustering characteristics represents the spatial effect of adjacent regions, clustering characteristics of rural areas and agriculture information level provide the foundation of information service radius, that is to say, high information level region tend to be clustered close to the high information level region, the low information level region tend to be clustered close to the low information level region. The gradients and continuity of rural areas and agriculture information level need explore the sound analysis by spatial model. In the study, the centroid coordinates extracted from 19 
country units on basis of spatial analysis were regarded as the data points of rural areas and agriculture information level. Owing to the gently varying of information level, the precision of interpolation surface was improved with the support of RBF, as showed in Fig.2.

On the whole, rural areas and agriculture information level in Yellow-river Delta has spatial variability, there is obvious gradients of information level from the weight value(-7.597) to the weight value(13.657) depending on RBF analysis of the comprehensive level in 19 country units. As shown in Figure 2, Bincheng district, the "sink" area of information level, the "peak" area around Dongying, the service radius of rural areas and agriculture information level by GIS calculations, about $30 \mathrm{Km}$. In order to upgrade the whole pattern of information service nodes and improve the service efficiency of information level, combining with the service radius, The comprehensive service node should be established in Bincheng district and the secondary service node should be set up in Wudi country, the kind of the spatial pattern had not only important decision significance, but also provided the foundation for constructing the better hierarchy service system of rural areas and agriculture information level in Yellow-river delta.

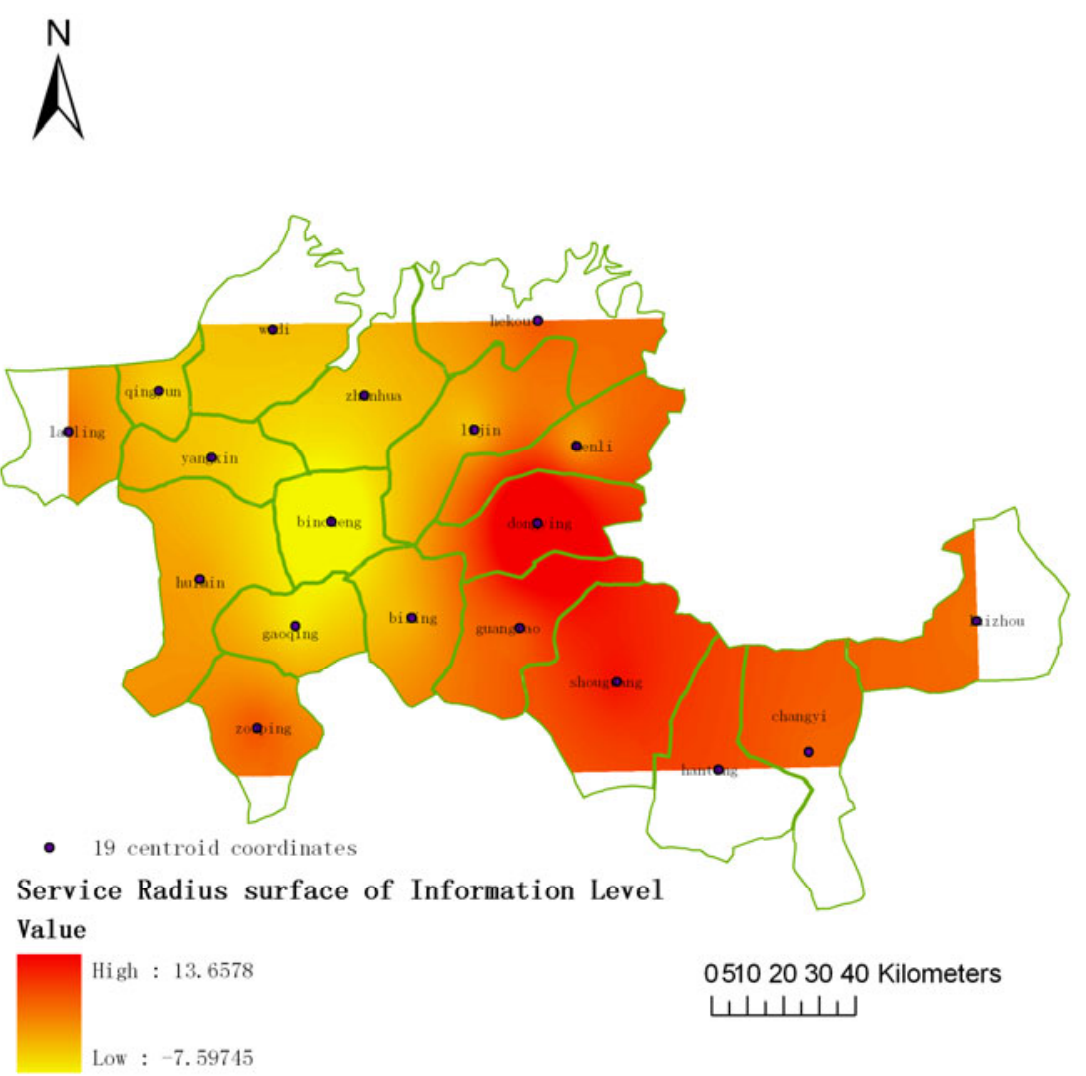

Fig. 2. The Service radius surface of rural areas and agriculture information level 
Based on GIS grid technology[18], as the foundation of centroid coordinates of 19 country units, according to the following sequence, Laizhou, Changyi, Hanting, Shouguang, Guangrao, Dongying, Kenli, Hekou, Lijin, Zhanhua, Wudi, Qingyun, Leling, Yangxin, Bincheng, Gaoqing, Boxing, Zouping and Hui min, the profile line of rural areas and agriculture information level was drawn, the results referred to Fig. 3 . Results showed that there is the fluctuation characteristics of rural areas and agriculture information level in Yellow river delta. The "peak" area is in Dongying and Shouguang, etc., the "sink" area is Bincheng district, the quantity description and sound fluctuation characteristics of information level is as the following contents, the weight value of the comprehensive information level referred to the brackets values, and represented the service level in different country units. Laizhou(0.707), Changyi(1.354), Hanting(2.456), Shouguang(4.592), Guangrao(1.947) Dongying(13.642), Kenli(-0.576), Hekou(1.678), Lijin(-2.249),Zhanhua(-2.879), Wudi(-2.358), Qingyun(-3.174), Leling(0.553), Yangxin(-2.806), Bincheng(-7.593), Gaoqing(-3.981), Boxing(-1.840), Zouping(1.791) and Hui $\min (-1.263)$.The profile line also indicated the information level of other regions excluded by 19 country units and there is the continuous distributions of information level, which is consistent with the service surface results of rural areas and agriculture information level from RBF surface results.

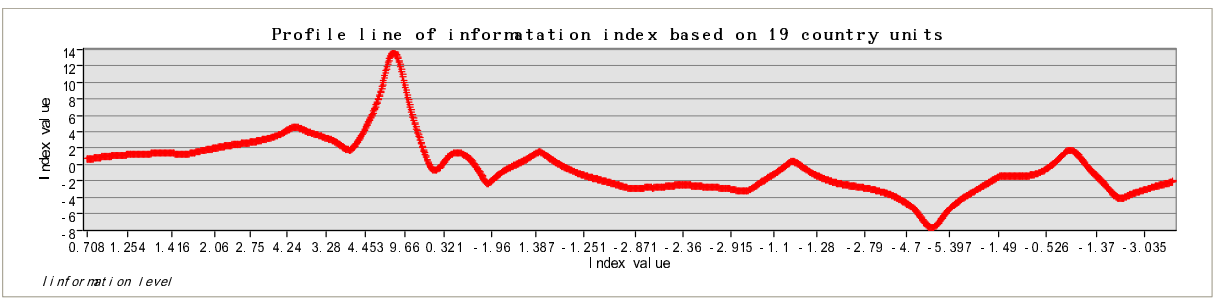

Fig. 3. The profile line of rural areas and agriculture information level in 19 country units

\section{Conclusions and Discussion}

The paper constructed 13 indices measured the rural areas and agriculture information level in Yellow-river Delta in 2007. Moran's I Coefficient analysis of rural areas and agriculture information level of 19 country units showed that the comprehensive information of 7 country units is significant, has the obvious spatial agglomeration and homogeneity characteristics, information level of Kenli and Zouping has the significant heterogeneity. The continued spatial surface from radial basis function method indicated that rural areas and agriculture information service in theory is $30 \mathrm{Km}$, the gradient and hierarchy is obvious. The comprehensive service node should be established in Bincheng district and promote the development of information level, the secondary service node should be set up in Wudi country for improving the service efficiency according to the study. Combining with GIS grid technology, the profile line results of rural areas and agriculture information service of centroid coordinates of 19 country units illustrated the fluctuation characteristics of the comprehensive information level. 
The service of rural and agricultural information is the inevitable trend of the world modern agricultural development, we should emphasize the comprehensive platform construction for rural areas and agriculture information services, support platform making full use of existing low-cost, mature means of communication and platform, multiple platform integrated organic body. In essence, the service construction of information platform of rural areas and agriculture information in Yellow-river delta is the branch platform and sub-nodes of the rural areas and agriculture information platform in Shandong province, so we should perfect the sound measurement system and the evaluation system of rural areas and agriculture information level, and especially measurement system on the regional scale, correspondingly, improve and strengthen the quality of rural areas and agriculture information service in demonstration site, promote the whole upgrading of the information level in Shandong province.

\section{References}

1. Zang, C., Chen, X., Liu, S., et al.: Present situation analysis of China rural informatization development. Journal of Hunan Agricultural University(Social Sciences) 4(5), 10-13 (2004) (in Chinese)

2. Liu, S.: Study on the indicator system for measuring the rural area information level in China. Library And Information Service 51(9), 33-35 (2007)

3. Mei, F.: Choice of development model of low-cost rural informationization in China. Journal of China Information Times (5), 12-13 (2007) (in Chinese)

4. Jing, D., Li, D., Li, H., Zhang, Y.: Research on assessment method for rural informatization level based on AHP. In: Li, D., Yang, S.X. (eds.) Computer and Computing Technologies in Agriculture II, vol. 24, pp. 125-134 (2010)

5. Lu, L.: Construction of index system for IT application in agriculture. Journal of Library and Information Sciences in Agriculture 19(4), 178-183 (2007)

6. Qin, X., Zhang, X., Zhang, X.: Study on assessment index system for rural informatization in Beijing. Journal of Beijing Agricultural Vocation College 22(1), 42-46 (2008)

7. Tan, G., He, W.: A study on contents, obstacles and countermeasures of rural informatization in China. Journal of Jiangxi Agricultural University 6(2), 86-88 (2007)

8. http://news.xinhuanet.com/politics/201001/31/content_12908364.htm

9. Wu, D.: Regional Analysis and Planning Turtorials. Education Press, Beijing (2004)

10. Statistical Bureau of Shandong Province, China county (city) Socio-economic Statistical Yearbook. China Statistics Press, Beijing (2008) (in Chinese)

11. Statistical Bureau of Shandong Province, Shandong Statistical Yearbook. China Statistics Press, Beijing (2008) (in Chinese)

12. $\mathrm{Pu}, \mathrm{Y} ., \mathrm{Ge}, \mathrm{Y} ., \mathrm{Ma}, \mathrm{R} ., \mathrm{Huang}, \mathrm{X}$., Ma, X.: Analyzing regional economic disparities based on ESDA. Geographical Research 24(6), 965-974 (2005) (in Chinese)

13. Wu, Y., Li, J.: A spatial econometric analysis of industrial total factor productivity in China's provincial regions. Scientia Geographica Sinica 26(4), 385-391 (2006) (in Chinese)

14. Anselin, L., Florax, R.J.G.M., Rey, S.J.: Advances in spatial econometrics: methodology, tools and applications. Springer, Berlin (2004) 
15. Stewart Fotheringham, A., Brunsdon, C., Charton, M.: Geographically weighted regression the analysis of spatially varying relationships

16. Haining, R.P.: Spatial data analysis: theory and practice. Cambridge University Press, Cambridge (2003)

17. Using ArcGIS Geostatistical Analyst. GIS by ESRI (2008)

18. Yang, Y., Zhu, J., Zhao, C., Liu, S., Tong, X.: The spatial continuity study of NDVI based on Kriging and BPNN algorithm. Mathematical and Computer Modelling (54), 1138-1144 (2011) 